\title{
Do All People Enjoy the Benefits from Technology Innovation?
}

\author{
Yoon Jeon Koh ${ }^{1}$, Jae Heon Park ${ }^{1}$, and Byung Do Chung ${ }^{2}$ \\ ${ }^{1}$ Economics \& Management Research Lab., kt, Sungnam, Korea \\ \{yoonjeon.koh, jaeheon. park\}@kt.com \\ ${ }^{2}$ Department of Systems Management Engineering, Sungkyunkwan University, Suwon, Korea \\ bd. chung@skku . edu
}

\begin{abstract}
The spread of emerging devices such as smartphone and Tablet PC enables people to experience an unprecedented technology innovation. However, some smartphone users show their intentions to reuse the feature phone due to the increased stress and pressure caused by a lot of functions of the smartphone. This study explores that the technology innovation doesn't provide all the people with the same level of values and satisfactions. A paper and pencil survey is employed with 3,798 mobile users randomly selected from 10's to 60 's in Korea and asks them to answer the devices, ICT services, and applications in use, and the degree of their satisfactions as well as their perceived values and reuse intentions. Results show that the effects of technology innovation are different depending on mobile users' perceived value of technology innovation and price-value scheme, satisfaction of mobile service in use, and ages.
\end{abstract}

Keywords: technology innovation, smartphone, perceived value, satisfaction.

\section{$1 \quad$ Introduction}

With the development of technology, the users of the emerging devices such as smartphone and tablet PC are rapidly growing. For example, the penetration rate of mobile phones in Korea has already surpassed $100 \%$ and about $60 \%$ of mobile phone users switched feature phones to smartphones in 3 years only after kt first introduced the iPhone into the Korean market in 2009. The tablet PC market is also growing in Korea, even though the usage rate is less than $20 \%$ out of the mobile phone users now.

The spread of emerging devices mentioned above enables people to experience an unprecedented technology innovation in User Interface (UI) such as voice search and touch-sensor screen. In addition, the technology innovation enables people to use diverse functions of the new devices in a simple and easy way. As a result, people become more enthusiastic for the UI which is regarded as a key factor to influence the competitiveness of the emerging devices, driving the direction of the technology development such as motion and voice sensing.

However, some smartphone users show their intentions to reuse the feature phone due to the increased stress and pressure caused by the smartphone such as frequent 
email checks and notification sounds. On the other hand, a newest smartphone with high-specification is a just useless device to those who are not familiar with applications and functions which are based on the new UI, or those who use only voice and text services with their mobile phones. Thus, this study attempts to explore that the technology innovation doesn't provide all the people with the same level of benefits, values, and satisfactions, which are influenced by their life style and attitudes toward the technology.

\section{$2 \quad$ Literature Review}

Research has been shown that customer satisfaction is an important factor positively influencing customer loyalty and post-purchase intention in telecommunication market (Kim et al., 2004; Kuo et al., 2009). However, customer satisfaction is a broad and complex concept, which can be viewed from various perspectives including price, product design and service quality. Product design and demographic factors have been investigated as influencing the level of customer satisfaction of a mobile phone. For example, Han et al. (2004) and Ling et al. (2007) investigated critical design features of a mobile phone affecting overall user satisfaction. Yuen et al. (2011) examined Malaysian citizens to indentify the demographic factors influencing customer satisfaction.

More attentions have been given to new characteristics and functionalities due to an increasing number of value-added features on current mobile phones, especially smartphones. A recent study by J.D. Power and Associates (2011) found that the key factors of overall satisfaction with a smartphone were not only design features such as a specific size and weight but latest technological advancement. Among the studies on the relationship between the new features and customer satisfaction, Park and Lee (2011) analyzed how user experience and device characteristics of smartphone affect customer satisfaction. In their pilot study, they showed that instant connectivity is the most important factor but smartphone stress and enjoyment aren't. Ling et al. (2006) showed that color screen, mobile Internet and voice dialing strongly impacted satisfaction level. Also, Haverila (2011) found that the most important feature is battery/talk time among male users. Dobrota et al. (2012) analyzed how customer satisfaction is related to the customers' foreknowledge, awareness and information about mobile operation system. Bayraktar et al. (2012) compared customer satisfaction and loyalty efficiency of six mobile phone brands in Turkish telecommunication market.

While a lot of research has focused on the relationships between new features of smartphone and customer satisfaction, some have shown the relationships between smartphone price and customer satisfaction. In Tan et al. (2012), the most important feature of a smartphone is price plans by telecom operators rather than other features including technology-related features, design-related features, application-related features and image-related features. Also, smartphone price is ranked $5^{\text {th }}$ among 11 smartphone features. Lee (2011) claimed that the price of a smartphone has no relationship with customer loyalty to the mobile service provider. 
According to Kuo et al. (2009), customer's perceived value is also closely related to customer satisfaction and can be considered from different perspectives including money, quality, benefit and social psychology ((Bishop (1984), Zeithaml (1988), Sheth (1991)). From the perspective of quality in mobile services, studies have investigated the perceived value of short message service (Lai (2004)), mobile commerce (Lin and Wang (2006)), mobile value-added services (Kuo et al. (2009)). In addition, self-disclosure, flow and social presence have been considered as affecting user satisfaction of instant mobile messenger in smartphone (Park et al. (2011)). However, few have explored the relationship between the satisfaction of smartphone and the perceived value of technology innovation of smartphone. Therefore, this study will explore how users' perceived value of technology innovation of smartphone affects their satisfaction of the smartphone, and include personal characteristics like price-value perception and the satisfaction of their mobile service provider as important factors.

\section{$3 \quad$ Research Model and Hypotheses}

The research model includes demographic and psychological variables determining users' satisfaction of their smartphones as shown in Fig. 1. We assumed that Perceived Value of Technology Innovation (PVTI) and Price-Value Perception (PVP) would determine Satisfaction of Smartphone (SS). We also hypothesized that demographic characteristics (Gender and Age) and users' satisfaction of their mobile services (SMS) would be related to Satisfaction of Smartphone (SS).

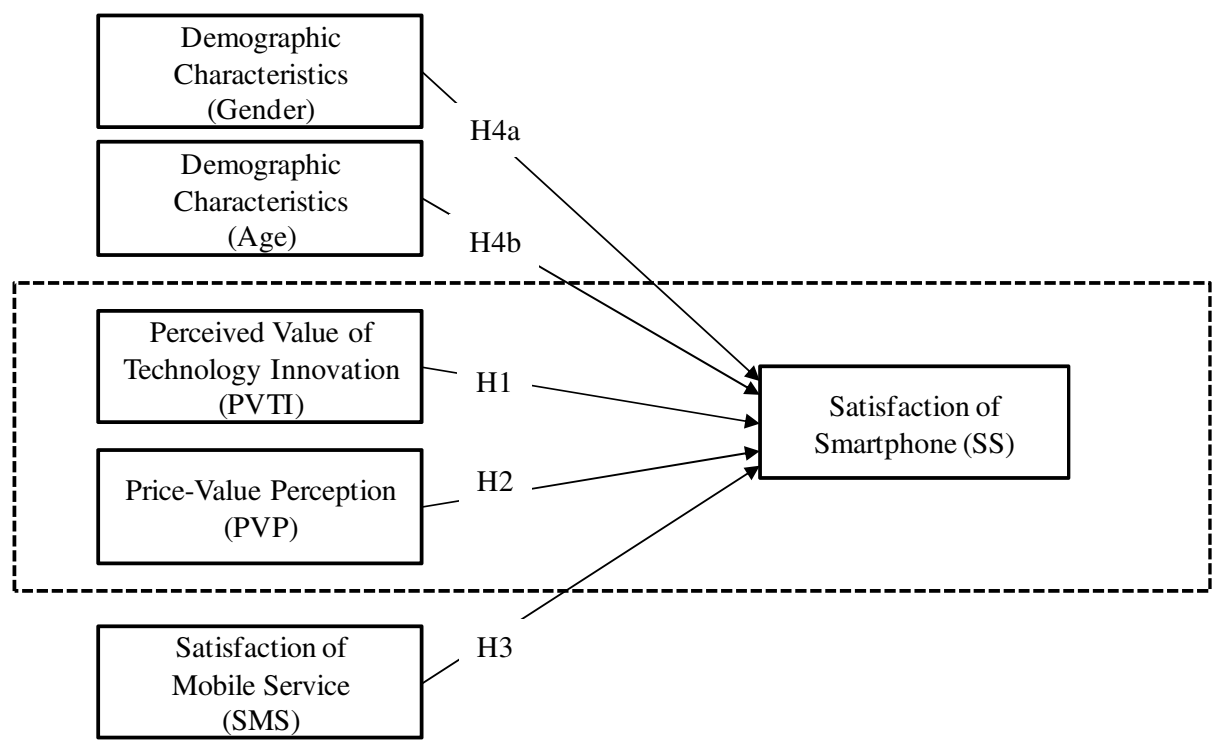

Fig. 1. Research Model 
Perceived Value of Technology Innovation (PVTI) of a mobile phone represents how much a smartphone user recognizes and utilizes the innovative value of a smartphone in contrast to a feature phone. The innovative value of a smartphone can be explained by the function of data communication. Although a feature phone also provides data communication services, they are very constrained compared to a smartphone. PVTI was measured in terms of the perceived ratio of the value of data communication in the whole value of smartphone and the perceived ratio of the value of application messenger in users' communication usages. Considering that customer's perceived value is related to customer satisfaction, we propose the first hypothesis:

Hypothesis 1. PVTI is positively related to SS.

In general, smartphone users pay higher telephone rates as well as use more expensive devices, compared to feature phone users. All smartphone users do not think that higher price provides higher value or quality, affecting the satisfaction of a smartphone. We measured Price-Value Perception (PVP) in terms of user's price-quality schema (Bearden et al., 2011). Therefore, the second hypothesis is:

Hypothesis 2. PVP is positively related to SS.

Mobile phone users use mobile voice and data communication services. Because functions of a mobile phone are realized based on a mobile telecommunication service, we assumed that SMS affects SS. Thus, we hypothesize the following:

Hypothesis 3. SMS is positively related to SS.

Utilities of technology are various according to users' demographic characteristics. In general, individual's gender and age are basic considerations in segmentation for marketing. It is important to examine the effect of users' gender and age on the satisfaction of a smartphone. Thus we propose the following hypotheses:

Hypothesis 4a. Gender is related to SS.

Hypothesis 4b. Age is related to SS.

\section{Methods}

This study employed a face-to-face survey to obtain 3,798 questionnaires. The respondents were randomly selected from all of major cities and provinces of Korea, according to the national demographic statistics. Thus, the survey data represents a summarization of nationwide characteristics of Koreans. Smart PLS was used in the analysis of this study. First, a measurement model was tested using confirmatory factor analysis. For the test, individual item reliability, internal consistency and discriminate validity were analyzed. After the measurement model test, a structural equation model was analyzed and the hypotheses were tested. 
Table 1. Characteristics of Respondents

\begin{tabular}{cccc}
\hline Category & & Frequency & Percentage (\%) \\
\hline \multirow{2}{*}{ Gender } & Male & 2003 & 52.7 \\
& Female & 1795 & 47.3 \\
\hline \multirow{5}{*}{ Age } & $13 \sim 19$ & 458 & 12.1 \\
& $20 \sim 29$ & 783 & 20.6 \\
& $30 \sim 39$ & 905 & 23.8 \\
& $40 \sim 49$ & 876 & 23.1 \\
& $50 \sim 59$ & 646 & 16.7 \\
& $60 \sim 69$ & 140 & 3.7 \\
Smartphone & M1 & 2099 & 55.3 \\
Manufacturer & M2 & 410 & 10.8 \\
& M3 & 448 & 11.8 \\
& M4 & 489 & 12.9 \\
\multirow{2}{*}{ Mobile } & Etc. & 352 & 9.3 \\
Service & T1 & 1898 & 50.0 \\
Provider & T2 & 1191 & 31.4 \\
& T3 & 677 & 17.8 \\
\hline
\end{tabular}

\section{$5 \quad$ Results}

\subsection{Reliability and Validity of Measures}

Individual item reliability was tested using factor loading of measured variables for each latent variable. If the factor loading of an item are greater than 0.5 , the item reliability is demonstrated. Composite reliability indexes were used to test internal consistency of latent variables. The acceptable level of composite reliability index is 0.7. To test the discriminant validity, the square root of AVE (Average Variance Extracted) was used. It should be greater than 0.5 to verify the discriminant validity. Table 2 shows the results of the reliability and validity test. Factor loadings are greater than 0.5 and the square root of AVE and composite reliability are greater than 0.5 and 0.7 , respectively. Thus, reliability of measured variables and discriminant validity of latent variables are justified.

\subsection{Analysis of the Structural Model}

Bootstrapping of Smart PLS was used to analyze the research model. Table 3 and Fig. 2 show the results. PVTI and PVP were positively related to users' satisfaction of smartphone (SS). The path coefficients of them are 0.100 and 0.091 , respectively, and p-values are less than 0.001. Thus, H1 and H2 are supported. SMS is found to be significantly related to SS. The path coefficient is 0.324 and p-value is less than 0.001. H3 is supported. The path between Gender and SS was found to be insignificant. The p-value is greater than 0.05 and thus $\mathrm{H} 4 \mathrm{a}$ is not supported. On the other hand, Age is related to SS. The path coefficient is 0.038 and p-value is less than 0.05 . 
Table 2. Results of Validity and Reliability Test

\begin{tabular}{lccc}
\hline & $\begin{array}{c}\text { Factor } \\
\text { Loading }\end{array}$ & $\begin{array}{c}\text { SQRT } \\
\text { (AVE) }\end{array}$ & $\begin{array}{c}\text { Composite } \\
\text { Reliability }\end{array}$ \\
\hline $\begin{array}{l}\text { Perceived Value of Technology Innovation } \\
\text { What do you think is the ratio of the value of mobile internet }\end{array}$ & 0.87 & 0.86 & 0.85 \\
$\begin{array}{l}\text { service among all of the services provided by mobile com- } \\
\text { munication? }\end{array}$ & & & \\
What do you think is the ratio of the usage of communication & 0.86 & & \\
though messenger application among all of your mobile \\
communication?
\end{tabular}

Table 3. Results of Hypotheses Test

\begin{tabular}{lcccc}
\hline Hypothesis & Path & $\begin{array}{c}\text { Path Coef- } \\
\text { ficient }\end{array}$ & t-value & p-value \\
\hline H1 & $\begin{array}{c}\text { Perceived Value of Technology Innovation } \\
\rightarrow \text { Satisfaction of Smartphone }\end{array}$ & 0.100 & 5.305 & 0.000 \\
H2 & $\begin{array}{l}\quad \text { Price Value Perception } \rightarrow \text { Satisfaction of } \\
\text { Smartphone }\end{array}$ & 0.091 & 4.966 & 0.000 \\
H3 & Satisfaction of Mobile Service $\rightarrow$ Satisfaction \\
of Smartphone & 0.324 & 18.508 & 0.000 \\
H4a & $\quad \begin{array}{c}\text { Gender } \rightarrow \text { Satisfaction of Smartphone } \\
\text { H4b }\end{array}$ & -0.018 & 1.200 & 0.237 \\
\hline
\end{tabular}




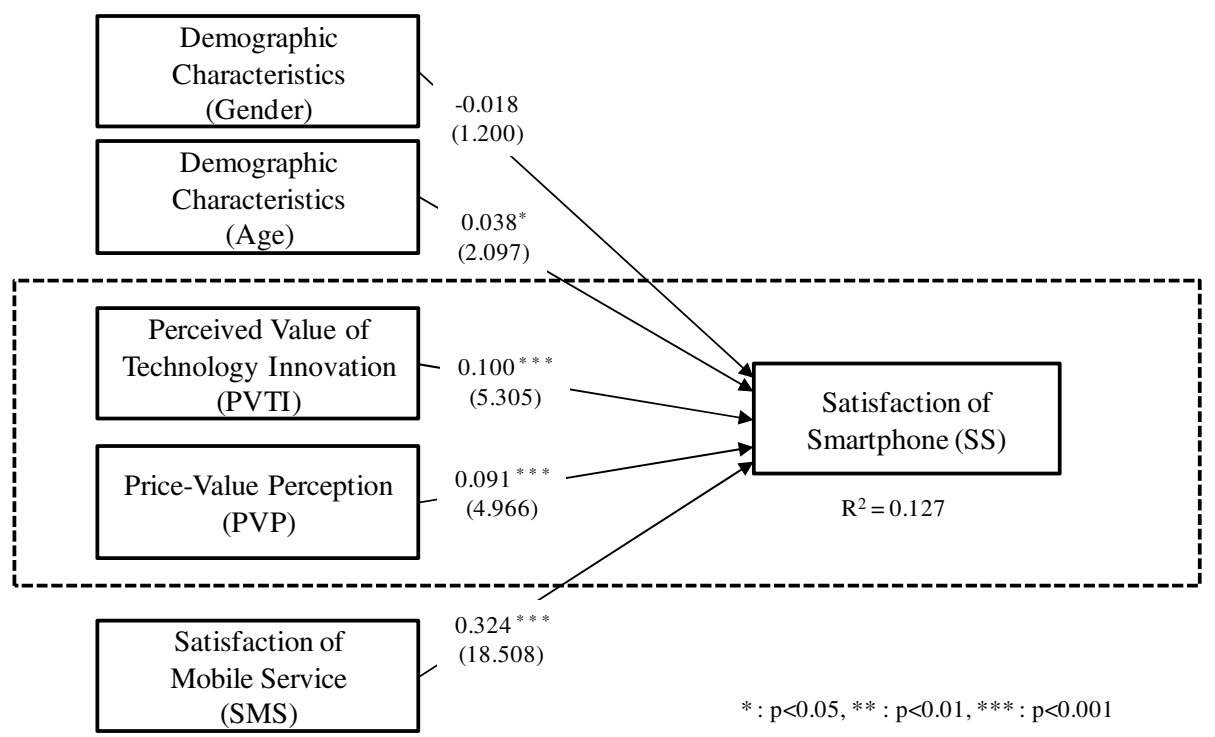

Fig. 2. Results of Research Model and Hypotheses Test

\section{Discussions}

\subsection{Summary of Findings}

This study provides a strong evidence that the satisfaction of smartphone is affected by the perceived value of technology innovation of a smartphone. Two measured variables, the value of mobile internet service and the ratio of the usage of communication through messenger application, were used and showed to be reliable to represent the perceived value. This means that although people accept new technology, they have different acceptance level of value provided by the technology and thus the satisfaction of a new technology is influenced by not only its features but also users' acceptance level.

Another finding is that the relationship between the price-value perception and the satisfaction of smartphone is significant. This means that some people may be dissatisfied by the high price although they get great value from technology innovation. A user's satisfaction with the mobile service provider he/she subscribes to is a significantly associated with the satisfaction of the smartphone. This shows that satisfaction of a technology which is enabled by another one is influenced by the other one. As expected, a user's age has a significant relation with the satisfaction of smartphone. On the other hand, the gender is not significantly related with the satisfaction of a smartphone. This shows that there are some other factors which are affecting on the satisfaction of a smartphone and have in relation with age but not with gender. 


\subsection{Contributions and Limitations}

This study expands the concept of perceived value by showing that people show the perceived value from the perspective of technology, in addition to that of money, quality, and benefit. The results show that the higher the perceive value of a smartphone is, the higher the satisfaction of smartphone is. Additionally, the findings suggest that individuals' price-value perception affects the satisfaction of smartphone.

This study also provides that the satisfaction with a telecom service provider affects the satisfaction of a smartphone, meaning that the satisfaction of a smartphone should be considered by the combination of the device and the service of a smartphone. Finally, findings suppose that all people do not fully enjoy the benefits from the technology innovation, showing that users have different acceptance levels of the smartphone value. Thus, different approaches and services should be prepared depending on the level of acceptance, in order to help people who do not easily follow and accept the technology innovation.

In spite of those contributions, this study has some limitations. Although the study supposes that the users' personal characteristics have a relation on the satisfaction of a smartphone, other factors were not considered except the price-value perception. Such as involvement and technology readiness can also be used as affecting factors. The model can be expanded to include users' intention to repurchase a smartphone to build a model explaining the relations from the perceived value to retention through satisfaction of technology innovation. These limitations should be our further works.

\section{References}

1. Kuo, Y.F., Wu, C.M., Deng, W.J.: The relationships among service quality, perceived value, customer satisfaction, and post-purchase intention in mobile value-added services. Computers in Human Behavior 25(4), 887-896 (2009)

2. Kim, M.K., Park, M.C., Jeong, D.H.: The effects of customer satisfaction and switching barrier on customer loyalty in Korean mobile telecommunication services. Telecommunications Policy 28(2), 145-159 (2004)

3. Han, S.H., Kim, K.J., Yun, M.H., Hong, S.W., Kim, J.: Identifying mobile phone design features critical to user satisfaction. Human Factors and Ergonomics in Manufacturing \& Service Industries 14(1), 15-29 (2004)

4. Park, Y., Chen, J.V.: Acceptance and adoption of the innovative use of smartphone. Industrial Management \& Data Systems 107(9), 1349-1365 (2007)

5. Ling, C., Hwang, W., Salvendy, G.: Diversified users' satisfaction with advanced mobile phone features. Universal Access in the Information Society 5(2), 239-249 (2006)

6. Yuen, Y.Y., Yeow, P.H., Connolly, R.: Mobile phone satisfaction in Malaysia: a demographic analysis. International Journal of Mobile Communications 9(4), 341-358 (2011)

7. Ling, C., Hwang, W., Salvendy, G.: A survey of what customers want in a cell phone design. Behaviour \& Information Technology 26(2), 149-163 (2007)

8. Dobrota, M., Milenković, I., Bulajić, M.: The Influence of Foreknowledge on Customers'Satisfaction With Mobile Operating Systems. Business Intelligence and Decision Making in Management 251 
9. Bayraktar, E., Tatoglu, E., Turkyilmaz, A., Delen, D., Zaim, S.: Measuring the efficiency of customer satisfaction and loyalty for mobile phone brands with DEA. Expert Systems with Applications 39(1), 99-106 (2012)

10. Bishop Jr., W.R.: Competitive intelligence. Progressive Grocer 63(3), 19-20 (1984)

11. Zeithaml, V.A.: Consumer perceptions of price, quality, and value: a means-end model and synthesis of evidence. The Journal of Marketing, 2-22 (1988)

12. Sheth, J.N., Newman, B.I., Gross, B.L.: Consumption values and market choices: Theory and applications, pp. 16-74. South-Western Pub. (1991)

13. Lai, T.L.: Service quality and perceived value's impact on satisfaction, intention and usage of short message service (SMS). Information Systems Frontiers 6(4), 353-368 (2004)

14. Lin, H.H., Wang, Y.S.: An examination of the determinants of customer loyalty in mobile commerce contexts. Information \& Management 43(3), 271-282 (2006)

15. Park, B.W., Lee, K.C.: A Pilot Study to Analyze the Effects of User Experience and Device Characteristics on the Customer Satisfaction of Smartphone Users. Ubiquitous Computing and Multimedia Applications, 421-427 (2011)

16. Park, S., Oh, D., Lee, B.G.: Analyzing user satisfaction factors for instant messenger-based mobile SNS. In: Park, J.J., Yang, L.T., Lee, C. (eds.) FutureTech 2011, Part II. CCIS, vol. 185, pp. 280-287. Springer, Heidelberg (2011)

17. Lee, J.W.: Critical factors promoting customer loyalty to smartphone and mobile communications service providers (2011)

18. Bearden, W.O., Netemeyer, R.G., Haws, K.L.: Handbook of Marketing Scales, 3rd edn., p. 379. SAGE Publications (2011)

19. Tan, W.K., Yi-Der Yeh, S.J.C., Lin, Y.C., Kuo, C.Y.: How Consumers Assess Product's Features?: A Case Study of Product Features of Smartphone. In: Proceedings of the 6th International Conference on Applied Mathematics, Simulation, Modelling, pp. 131-137. World Scientific and Engineering Academy and Society, WSEAS (March 2012)

20. Power, J.D.: The Right Blend of Design and Technology is Critical to Creating an Exceptional User Experience with Smartphones and Traditional Mobile Devices. JD Power and Associates (2011) 